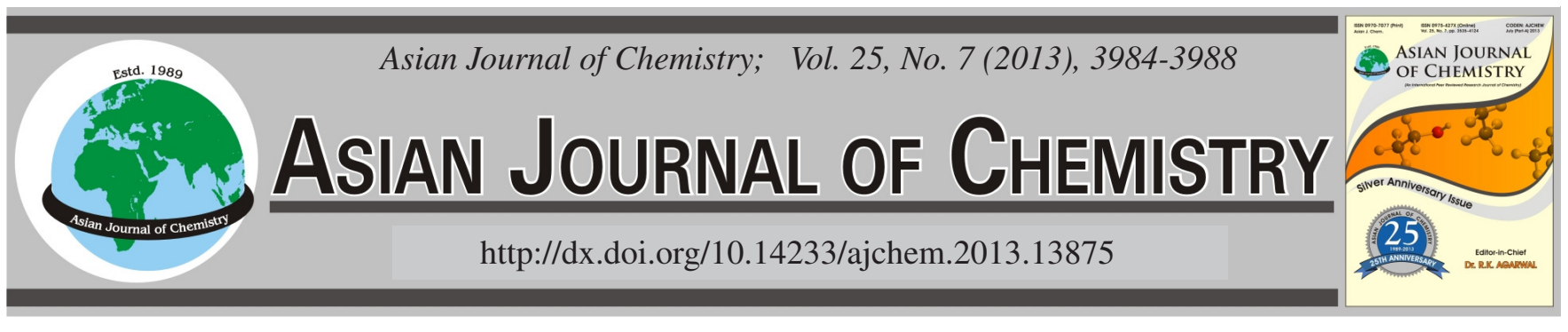

\title{
Ionic Liquid-Based Dispersive Liquid-Liquid Microextraction Combined with Flame Atomic Absorption Spectrometry for Determination of Silver in Water Samples
}

\author{
M. Dehghani Mohammad Abadi ${ }^{*}$, M. Chamsaz and M.H. Arbab-Zavar
}

Department of Chemistry, Faculty of Sciences, Ferdowsi University of Mashhad, Mashhad, Iran

*Corresponding author: Fax: +98 511 8796416; Tel: +98 511 8795162; E-mail: mdmanalyst@yahoo.com

\begin{abstract}
A new, simple and highly sensitive dispersive liquid-liquid microextraction method using an ionic liquid, 1-butyl-3-methylimidazolium hexafluorophosphate $\left(\left[\mathrm{C}_{4} \mathrm{MIM}\right]\left[\mathrm{PF}_{6}\right]\right)$, for silver determination at trace levels was developed by flame atomic absorption spectrometry in water samples. Diethyl dithiocarbamate (DDTC) was employed as a chelating agent to form Ag-DDTC complex for extracting silver ions from aqueous solution into the fine droplets of $\left[\mathrm{C}_{4} \mathrm{MIM}\right]\left[\mathrm{PF}_{6}\right]$. Some effective factors influencing the microextraction efficiency include the $\mathrm{pH}$, the diethyl dithiocarbamate concentration, type and volume of disperser solvent, the amount of ionic liquid, the ionic strength and the centrifugation time were investigated and optimized. At the optimum experimental conditions, the limit of detection based on $3 \mathrm{~S}_{\mathrm{b}} \mathrm{bas}$ $3.0 \mu \mathrm{g} \mathrm{L}{ }^{-1}$. The relative standard deviation for five replicate determinations of $200 \mu \mathrm{g} \mathrm{L}^{-1} \mathrm{Ag}$ was $2.9 \%$. The calibration graph was linear in the range of $15-300 \mu \mathrm{g} \mathrm{L}^{-1}$ with a correlation coefficient of 0.9961 . The applicability of the proposed method was evaluated by determination of trace amounts of silver in water samples.
\end{abstract}

Key Words: Flame atomic absorption spectrometry, Ionic liquid, Dispersive liquid-liquid microextraction, Water samples.

\section{INTRODUCTION}

The widespread use of silver compounds and silvercontaining procedures in industry, medicine, jewellery, cloud seeding and in disinfection of drinking water has resulted in an increasing silver content in environmental samples. Silver impregnated filters are used in water disinfection, while silver concentrations up to $200 \mu \mathrm{g} \mathrm{L}{ }^{-1}$ are permitted for antimicrobial activities for human health ${ }^{1}$. Silver often is presented as an impurity in $\mathrm{Cu}, \mathrm{Zn}$, As and $\mathrm{Sb}$ ores and thus it is possible to be entered into the environment from industrial wastes ${ }^{2,3}$. Bowen ${ }^{4}$ suggested that silver may pose a potential risk as a water pollutant, because of the lack of recycling of mined silver. The recent information about the interaction of silver with essential nutrients, especially selenium, copper and vitamins E and B12, has focused attention on its potential toxicity ${ }^{1}$. Consequently, determination of trace amounts of silver is important for many areas of chemical analysis 5 . Ultra trace amount of silver ions in environmental samples is a stimulant for applying preconcentration techniques prior to its determination ${ }^{6,7}$. The most widely used techniques for separation and preconcentration of trace amount of silver ions are coprecipitation ${ }^{8}$, solid-phase extraction $(\mathrm{SPE})^{9,10}$, liquid-liquid extraction (LLE) $)^{11}$, cloud point extraction $(\mathrm{CPE})^{12}$, etc. Liquid-liquid extraction is one of the widely used preconcentration and matrix isolation techniques for determination of metal ions. Although it offers high reproducibility and high sample capacity, it is considered to be a time and labor consuming procedure. It also has the tendency for emulsion formation and uses large amounts of hazardous and costly organic solvents. To overcome these problems, microextraction methods such as drop-in-drop system $^{13}$, single-drop microextraction (SDME) ${ }^{14,15}$, homogenous liquid-liquid microextraction (HLLME) ${ }^{16}$, solid phase microextraction (SPME) ${ }^{17,18}$ and dispersive liquid-liquid microextraction (DLLME) ${ }^{19-21}$ has been developed ${ }^{22}$. Microextraction techniques are very useful and popular for preconcentration and separation of organic and inorganic contaminantsin environmental samples at trace levels in the last 10 years $^{23-29}$ due to the advantages of simple procedure, high extraction efficiency and low consumption of toxic organic solvents ${ }^{30}$. Room temperature ionic liquids (RTILs) with negligible vapor pressure and good selective solubility have aroused increasing interests for their promising role as an alternative solvents in synthesis, separation and electrochemistry ${ }^{31}$. These properties make them good for extraction of various organic compounds and metal ions as neutral or charged complexes, which is very attractive in separation processes ${ }^{32-36}$. Various works have been successfully employed as replacement solvents to separate organic compounds (phenolic compounds, biofuels and amino acids) ${ }^{37}$, biologically important molecules (carbohydrates, 
organic acids and DNA $)^{37,38}$ and metal ions ${ }^{39,40}$. Several efforts have been made based on extraction with an ionic liquid, such as ionic liquid-based headspace liquid phase microextraction ${ }^{41}$, ionic liquid-based single-drop microextraction ${ }^{42,43}$, ionic liquid-based headspace single-drop microextraction ${ }^{44}$, cold induced aggregation microextraction ${ }^{45}$ and temperaturecontrolled ionic liquid dispersive liquid phase microextraction $^{46,47}$. These methods present outstanding figures of low consumption of volatile organic solvents and high enrichment factors ${ }^{48}$

In the present work, the room temperature ionic liquid 1-butyl-3-methylimidazolium hexafluorophosphate, $\left[\mathrm{C}_{4} \mathrm{MIM}\right]\left[\mathrm{PF}_{6}\right]$, was employed as a solvent for the extraction of Ag-diethyl dithiocarbamate complex. The extracted final phase was diluted with $400 \mu \mathrm{L}$ ethanol and was aspirated into the flame atomic absorption spectrometer. The applicability of the method has been demonstrated for determination of silver in water samples. The effect of various experimental conditions on the extraction of silver were investigated and discussed.

\section{EXPERIMENTAL}

Shimadzu AA-670 (Shimadzu, Japan) flame atomic absorption spectrometer was utilized, equipped with a $100 \mu \mathrm{m}$ burnerhead, deuterium background correction and an air-acetylene flame. A silver hollow-cathode lamp (Hamamatsu Photonics, Shizuoka, Japan) at wavelength of $328.1 \mathrm{~nm}$ was used as a radiation source, operated at $10 \mathrm{~mA}$ with a monochromator spectral bandpass of $0.2 \mathrm{~nm}$.

The $\mathrm{pH}$ values were measured with a $\mathrm{pH}$-meter (Metrohm, 632) supplied with a glass-combined electrode.

A stock solution of silver at a concentration of $1000 \mathrm{mg}$ $\mathrm{L}^{-1}$ was prepared by dissolving appropriate amounts of $\mathrm{AgNO}_{3}$ (Merck, Darmstadt, Germany) in $1 \mathrm{M}$ nitric acid solution and stored in dark. 1-Butyl-3-methylimidazolium hexafluorophosphate $\left[\mathrm{C}_{4} \mathrm{MIM}\right]\left[\mathrm{PF}_{6}\right]$ ) was purchased from Merck (Darmstadt, Germany), $1 \%$ (m/v) sodium diethyl dithiocarbamate solution was prepared by dissolving the appropriate amounts of NaDDC (Merck) in deionized water. Triton X-114 was purchased from Fluka (Busch, Switzerland).

Ionic liquid-based dispersive liquid-liquid microextraction procedure and subsequent flame atomic absorption spectrometry: For dispersive liquid-liquid microextraction under the optimum conditions, $10 \mathrm{~mL}$ of the sample solution containing $\mathrm{Ag}^{+}$and $5 \mathrm{~mL}$ of $1 \%(\mathrm{~m} / \mathrm{v})$ diethyl dithiocarbamate (DDTC) were adjusted at $\mathrm{pH} 2.5$ in a glass test tube with a conical bottom. Then Triton X-114 (0.01\% w/v) and binary solution containing $600 \mu \mathrm{L}$ of acetone (disperser solvent) and $0.25 \mathrm{~g}$ of $\left[\mathrm{C}_{4} \mathrm{mim}\right]\left[\mathrm{PF}_{6}\right]$ (extraction solvent) was rapidly injected into the sample solution by using $1.0 \mathrm{~mL}$ syringe and a stable cloudy solution (water, acetone and ionic liquid) was obtained. The Ag-DDTC complex was extracted into fine droplets of ionic liquid. The mixture was then centrifuged for $4 \mathrm{~min}$ at $4000 \mathrm{rpm}$. After this process, the fine droplets of $\left[\mathrm{C}_{4} \mathrm{mim}\right]$ $\left[\mathrm{PF}_{6}\right]$ were joined together and settled at the bottom of the conical test tube. After removal of the whole aqueous solution the extraction phase was diluted with $400 \mu \mathrm{L}$ of ethanol and was aspirated into the flame atomic absorption spectrometer.
It was observed that after centrifugation, some of the ionic liquid-phase sticks onto the wall of the centrifuge tube. In order to overcome this problem, non-ionic surfactants were added to the sample solutions. In presence of the non-ionic surfactants, molecules of the surfactant surround the fine droplets of ionic liquid, during phase separation and hence, interactions of ionic liquid with the wall of the centrifuge tube decreased and consequently, the ionic liquid-phase did not stick to the wall of the centrifuge tube. The effect of non-ionic surfactant Triton X-114 was investigated and compared. In the presence of Triton X-114 recovery was increased. Therefore, a concentration of $0.01 \%$ $(\mathrm{w} / \mathrm{v})$ Triton X-114 was used in all of experiments ${ }^{45}$.

Sample preparation: To evaluate the efficiency of the proposed IL-DLLME method, two water samples including tap water and river water, were selected and the proposed ILDLLME method was applied to determine their silver content. The tap water sample obtained from our laboratory (University of Mashhad, Mashhad, Iran) and the river water sample from golnabdare river (Iran). The samples were collected in cleaned polyethylene bottles. Finally, the proposed method was applied to extract silver ions from the water samples.

\section{RESULTS AND DISCUSSION}

Effect of pH: The separation of metal ions by IL-based DLLME involves a prior formation of a complex with sufficient hydrophobicity and a subsequent extraction into the small volume of the sedimented phase. The $\mathrm{pH}$ value plays a unique role on both the metal-chelate formation and extraction. The effect of $\mathrm{pH}$, in the range of 1.5-8.0, adjusted with nitric acid and sodium hydroxide on the Ag-DDTC complex formation and the extraction of silver in water samples was investigated. The results showed that the extraction efficiency was increased up to $\mathrm{pH} 3$ and then declined at higher pHs. Thus, the $\mathrm{pH}$ value of 2.5 was selected as the optimum value.

Selection of disperser solvent: For IL-based DLLME method, the disperser solvent should be miscible with both water (aqueous phase) and the extractant solvent $\left(\left[\mathrm{C}_{4} \mathrm{mim}\right]\left[\mathrm{PF}_{6}\right] \mathrm{IL}\right)$. For this purpose, different solvents such as acetonitrile, acetone, ethanol and methanol were tested. Several sample solutions were studied using $600 \mu \mathrm{L}$ of each disperser solvent, containing $0.24 \mathrm{~g}$ of $\left[\mathrm{C}_{4} \mathrm{mim}\right]\left[\mathrm{PF}_{6}\right] \mathrm{IL}$. The maximum absorbance was obtained using acetone and hence it was selected as disperser solvent in all of the subsequent experiments.

Effect of chelating agent concentration: NaDDTC was used as the chelating agent due to the highly hydrophobic nature of its metal chelates. Concentration of chelating agent is a critical variable to be optimized in a pre-concentration method. The results showed the effect of NaDDTC concentration on the micro-extraction of silver ions. The concentration of NaDDTC tested ranged from $0.2-0.8 \%(\mathrm{~m} / \mathrm{v})$. The extraction efficiency for $\mathrm{Ag}$ ions increased as the concentration of NaDDTC increased from $0.2-0.4 \%(\mathrm{~m} / \mathrm{v})$ and then leveled off up to $0.6 \%(\mathrm{~m} / \mathrm{v})$ with a continuous decrease afterwards. Therefor e, a $0.5 \%(\mathrm{~m} / \mathrm{v})$ NaDDTC concentration was employed for further experiments.

Selection of ionic liquid: Ionic liquids are composed of unsymmetrically substituted nitrogen containing cations (e.g., 
imidazole, pyrrolidine and pyridine) with inorganic anions (e.g., $\mathrm{Cl}^{-}, \mathrm{BF}_{4}^{-}, \mathrm{PF}_{6}^{-}$and $\left.\left(\mathrm{CF}_{3} \mathrm{SO}_{2}\right)_{2} \mathrm{~N}^{-}\right)^{49}$. The ionic liquid used in DLLME must be water-immiscible. In addition, ionic liquid should be liquid at the experimental conditions and have high density so that fine particles of ionic liquid can settle down in saline solutions. Short alkyl chain imidazolium-based ionic liquids containing $\mathrm{Cl}^{-}, \mathrm{BF}_{4}^{-}$and $\mathrm{CF}_{3} \mathrm{SO}_{3}{ }^{-}$are water-miscible and ionic liquids containing $\mathrm{PF}_{6}^{-}$and $\left(\mathrm{CF}_{3} \mathrm{SO}_{2}\right)_{2} \mathrm{~N}^{-}$are waterimmiscible. According to the above criteria and the cost of 1-butyl-3-methylimidazolium hexafluorophosphate $\left(\left[\mathrm{C}_{4} \mathrm{mim}\right]\left[\mathrm{PF}_{6}\right]\right)$ was selected as the extracting solvent.

Effect disperser solvent and ionic liquid: The effect of the volume of acetone on the extraction recovery was also studied in the range of 400-700 $\mu \mathrm{L}$. The high recovery for Ag was achieved using $600 \mu \mathrm{L}$ and was chosen as the optimum volume as shown in Fig. 1.

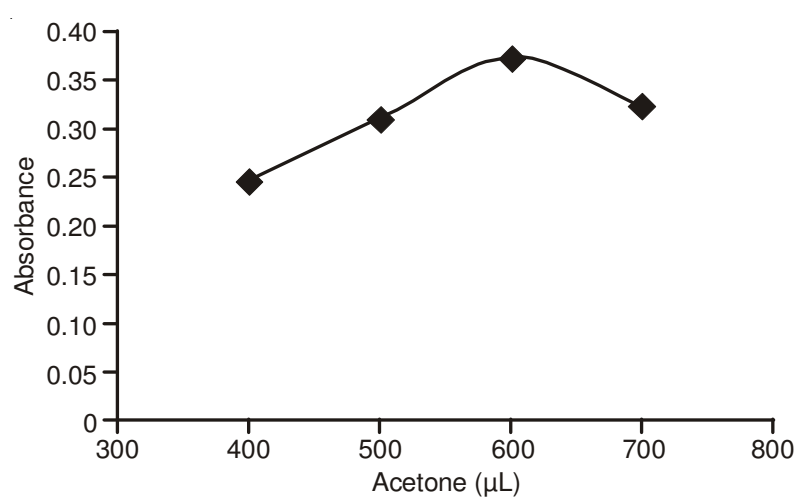

Fig. 1. Effect of volume of disperser solvent (acetone) on the absorbance of silver. Conditions: sample volume: $10 \mathrm{~mL},\left[\mathrm{C}_{4} \mathrm{mim}\right]\left[\mathrm{PF}_{6}\right]: 0.24$ g, pH: 2.5, DDTC concentration: $0.5 \%(\mathrm{~m} / \mathrm{v})$, concentration silver: $200 \mu \mathrm{g} \mathrm{L}^{-1}$, Triton X-114: $0.01 \%(\mathrm{w} / \mathrm{v})$

The viscosity of ionic liquids is high and its handling is difficult, so working solutions $\left(\left[\mathrm{C}_{4} \mathrm{mim}\right]\left[\mathrm{PF}_{6}\right]\right.$, were prepared in acetone. The amount of $\left[\mathrm{C}_{4} \mathrm{mim}\right]\left[\mathrm{PF}_{6}\right]$ IL used in this preconcentration procedure is a critical factor for obtaining high recovery of the analyte and, at the same time, obtaining a high volume ratio of the phases. Therefore the extraction system was carefully studied in order to define the lowest ionic liquid-phase mass necessary for achieving the highest possible preconcentration factor. The variation in the recovery as a function of the amount of ionic liquid, was investigated in the range of $0.24-0.28 \mathrm{~g}$. It was observed that the extraction efficiency of the proposed system was affected significantly by the ionic liquid amount. By increasing the $\left[\mathrm{C}_{4} \mathrm{mim}\right]\left[\mathrm{PF}_{6}\right]$ amount, the absorbance of Ag initially increased up to $c a .0 .25$ $\mathrm{g}$ of $\left[\mathrm{C}_{4} \mathrm{mim}\right]\left[\mathrm{PF}_{6}\right]$ and then started to decrease (Fig. 2), which was due to an increase in the volume of settled ionic liquidphase. By increasing the volume of settled ionic liquid-phase, viscosity of the ionic liquid-ethanol mixture increases. When the viscosity of solution aspirated into the flame of the atomic absorption spectrometer is high, the nebulizer uptake rate and therefore the absorbance decreases. Therefore, $0.25 \mathrm{~g}$ of $\left[\mathrm{C}_{4} \mathrm{mim}\right]\left[\mathrm{PF}_{6}\right]$ was chosen as the optimum value.

Influence of centrifugation time: The effect of centrifugation time was investigated by varying the time from 3-10 min which showed that 4 min centrifugation time at $4000 \mathrm{rpm}$

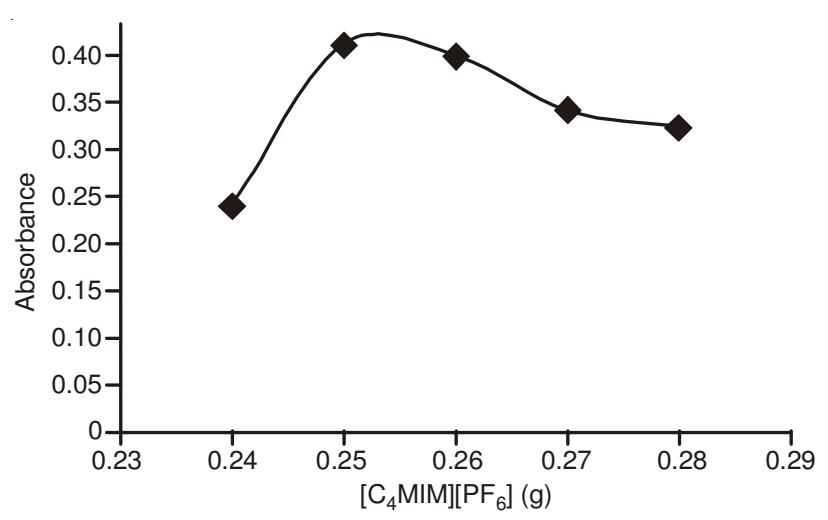

Fig. 2. Effect of amount of $\left[\mathrm{C}_{4} \mathrm{mim}\right]\left[\mathrm{PF}_{6}\right]$ on the absorbance of silver. Conditions: sample volume: $10 \mathrm{~mL}$, disperser solvent(acetone): 600 $\mu \mathrm{L}, \mathrm{pH}: 2.5$, DDTC concentration: $0.5 \%(\mathrm{~m} / \mathrm{v})$, concentration silver: $200 \mu \mathrm{g} \mathrm{L}{ }^{-1}$, Triton X-114: $0.01 \%$ (w/v)

resulted in highest sensitivity. The short centrifugation time did not ensure the phase separation, while longer centrifugation time made the ionic liquid to be dissolved in water phase again.

Effect of ionic strength: To investigate the influence of ionic strength on the microextraction performance, various experiments were performed by adding different amounts of $\mathrm{NaNO}_{3}(0-0.5 \mathrm{M})$. The results showed that an increase in the ionic strength will decrease the efficiency of extraction procedure. Addition of salt at high concentrations will increase the density of the solution and thus the extracted phase could not be settled down.

Effect of coexisting ion: In order to demonstrate the selectivity of the developed microextraction method to the determination of silver, the effect of common coexistence ions on silver determination was investigated and the potential interference in the IL-DLLME method due to the competition of other metal ions for the chelating agent and their subsequent co-extraction with $\mathrm{Ag}^{+}$was evaluated. In these experiments, interfering species at 100 fold excess were added to the test solutions containing $200 \mu \mathrm{g} \mathrm{L} \mathrm{L}^{-1}$ of silver followed by the general procedure. An ion was considered to interfere when its presence produced a variation of more than $\pm 5 \%$ in the absorbance of the sample. The results are given in Table- 1 . Most of the cations examined did not interfere in extraction and determination of $\mathrm{Ag}^{+}$. However, some species, such as $\mathrm{Pb}^{2+}, \mathrm{Cu}^{2+}, \mathrm{Au}^{3+}$ interfered with the determination of $\mathrm{Ag}^{+}$. These interferences were eliminated in the presence of a proper masking agent, such as EDTA.

\begin{tabular}{cc|cc}
\multicolumn{4}{c}{ TABLE-1 } \\
\multicolumn{4}{c}{ EFFECT OF DIVERSE IONS ON THE } \\
DETERMINATION OF 200 $\left(\mu \mathrm{g} \mathrm{L}^{-1}\right)$ SILVER \\
\hline $\begin{array}{c}\text { Coexisting } \\
\text { ions }\end{array}$ & Relative error & Coexisting & Relative error \\
$\mathrm{Na}^{+}$ & $(\%)$ & ions & $(\%)$ \\
$\mathrm{Zn}^{2+}$ & -0.30 & $\mathrm{Cu}^{2+}$ & -14.6 \\
$\mathrm{Cd}^{2+}$ & 2.80 & $\mathrm{Co}^{2+}$ & -1.51 \\
$\mathrm{Ni}^{2+}$ & -1.96 & $\mathrm{Au}^{3+}$ & -80.00 \\
$\mathrm{~Pb}^{2+}$ & -4.80 & $\mathrm{Cl}^{-}$ & -4.20 \\
$\mathrm{Cr}^{2+}$ & -31.80 & $\mathrm{NO}_{3}^{-}$ & -0.10 \\
$\mathrm{Mn}^{2+}$ & -2.50 & $\mathrm{SO}_{4}{ }^{2-}$ & -0.60 \\
$\mathrm{Fe}^{3+}$ & -0.45 & $\mathrm{CO}_{3}{ }^{2-}$ & -0.40 \\
\hline
\end{tabular}


Analytical figures of merit: The analytical performance of IL-DLLME coupled with FAAS for pre-concentration and determination of silver in water samples was systematically investigated under the optimized experimental conditions. The results exhibited that there was an excellent linear range in the concentration of silver from $15-300 \mu \mathrm{g} \mathrm{L}^{-1}$ and good correlation coefficient of 0.9961 . The LOD was $3.0 \mu \mathrm{g} \mathrm{L}^{-1}$ based on $3 \mathrm{~S}_{\mathrm{b}}$ with a relative standard deviation (RSD) of $2.9 \%(n=5, C=$ $200 \mu \mathrm{g} \mathrm{L}^{-1}$ ). The enhancement factor, calculated as the ratio of the calibration curve slopes for Ag after and before the preconcentration step, was 22 for $10.0 \mathrm{~mL}$ sample solution.

Determination of silver in real samples: The procedure was applied to determine silver ions in tap water and river water. Reliability was performed using the spiked procedure. The results are given in Table- 2 showing high recovery of spiked samples which demonstrates the applicability of the method for determination of silver in the sample type examined.

TABLE 2

ANALYSIS OF SILVER IN WATER SAMPLES

\begin{tabular}{cccc}
\hline Samples & Spiked $\left(\mu \mathrm{g} \mathrm{L}^{-1}\right)$ & Found $\left(\mu \mathrm{g} \mathrm{L}^{-1}\right)$ & Recovery $(\%)$ \\
\hline \multirow{2}{*}{ Tap water } & 0.0 & $\mathrm{BLR}^{\mathrm{a}}$ & - \\
& 90.0 & $91.6 \pm 3.60$ & 101.8 \\
\hline \multirow{2}{*}{ River water $^{\mathrm{b}}$} & 0.0 & $\mathrm{BLR}^{\mathrm{a}}$ & - \\
& 90.0 & $92.8 \pm 3.5$ & 103.1 \\
\hline \multirow{3}{*}{ Mineral water } & 0.0 & $\mathrm{ND}^{\mathrm{c}}$ & - \\
& 80.0 & $78.6 \pm 2.6$ & 98.2 \\
& 60.0 & $61.4 \pm 3.1$ & 102.3 \\
\hline
\end{tabular}

${ }^{\mathrm{a}}$ Below of linear range. ${ }^{\mathrm{b}}$ Golnabdare river. ${ }^{\mathrm{c}}$ Not detected.

\section{Conclusion}

The microextraction method based on ionic liquid dispersive liquid-liquid microextraction of traces silver as diethyl dithiocarbamate chelate in water samples is proposed as a prior step to their determination by flame atomic absorption spectrometry. This method is simple, rapid, sensitive and has low toxicity, since only very small amounts of an ionic liquid as a 'green extraction solvent' is used instead of environment damaging organic solvents. In addition, owing to high viscosity of ionic liquids, removing the bulk aqueous phase is easier and this method is more suitable for extraction of heatsusceptible species in comparison with cloud point extraction. The sensitivity of the method could be enhanced by using GFAAS as the detection system. The proposed method was successfully applied to monitor low concentrations of silver in water samples with good accuracy and precision. A comparison of the proposed method and some of the published methods for extraction and determination of silver are summarized in Table- $3^{5,50-54}$. As shown in Table- 3 , the detection limit, linear range, extraction time of the represented method is comparable to those in reported methods.

\section{ACKNOWLEDGEMENTS}

The authors thank Ferdowsi University of Mashhad for the financial support of this work. (code:15604/3 dated: March 2011).

\section{REFERENCES}

1. Environment Protection Agency (EPA), Ambient Water Quality Criteria for Silver, EPA 4405-80-071, Office of Water Regulations, Washington, DC (1980).

2. R. Soager, Metallic Raw Materials Dictionary, Bank Tobel, Zurich (1984).

3. M.M. Gomez, M.M.H. Garsia and M.A.P. Corvillo, Analyst, 120, 1911 (1995).

4. H.J.M. Bowen, Trace Element Biochemistry, Academic Press, London (1996).

5. S.Z. Mohammadi, D. Afzali, M.A. Taher and Y.M. Baghelani, Talanta, 80, 875 (2009).

6. C.C. Huang and M.H. Yang, Anal. Chem., 69, 3930 (1997).

7. C.H. Lee, J.S. Kin, M.Y. Suh and W. Lee, Anal. Chim. Acta, 339, 303 (1997).

8. D.S.K. Peker and O. Turkoglu, J. Hazard. Mater., 143, 555 (2007)

9. M. Ghaedi, M. Montazerozohori and M. Soylak, J. Hazard. Mater., 142, 368 (2007).

10. E. Vereda-Alonso, M.T. Siks-Cordero, A. Garcia-Detorres and J.M. Canopavon, Anal. Bioanal. Chem., 385, 1178 (2006).

11. J. Wang and E.H. Hansen, J. Anal. Atom. Spectrom., 17, 1284 (2002).

12. J. Chen, S. Xiao, X. Wu, K. Fang and W. Liu, Talanta, 67, 992 (2005).

13. H.G. Liu and P.K. Dasgupta, Anal. Chem., 68, 1817 (1996).

14. M.A. Jeannot and F.F. Cantwell, Anal. Chem., 68, 2236 (1996).

15. L. Xia, B. Hu, Z. Jiang, Y. Wu and Y. Liang, Anal. Chem., 76, 2910 (2004).

16. A.R. Ghiasvand, S. Shadabi, E. Mohagheghzadeh and P. Hashemi, Talanta, 66, 912 (2005).

17. C.L. Arthur and J. Pawliszyn, Anal. Chem., 62, 2145 (1990).

18. T. Kumazawa, X.P. Lee, K. Sato and O. Suzuki, Anal. Chim. Acta, 492, 249 (2003)

19. M. Rezaee, Y. Assadi, M.R. Milani-Hosseini, E. Aghaee, F. Ahmadi and S. Berijani, J. Chromatogr. A, 1116, 1 (2006).

20. S. Berijani, Y. Assadi, M. Anbia, M.R. Milani-Hosseini and E. Aghaee, J. Chromatogr. A, 1123, 1 (2006).

21. E. Zeini-Jahromi, A. Bidari, Y. Assadi, M.R. Milani-Hosseini and M.R. Jamali, Anal. Chim. Acta, 585, 305 (2007).

22. D. Afzali, A.R. Mohadesi, B. Bahadori Jahromi and M. Falahnejad, Anal. Chim. Acta, 684, 54 (2011).

23. Z. Eshaghi and R. Azmoodeh, Arabian J. Chem., 3, 21 (2010).

24. Q.Y. Chang, J.W. Zhang, X. Du, J.J. Ma and J.C. Li, Front. Environ. Sci. Eng. Chin., 4, 187 (2010).

25. M. Rezaee, Y.Yamini, A. Khanchi, M. Faraji and A. Saleh, J. Hazard. Mater., 178, 766 (2010).

26. Y. Yamini, M. Rezaee, A. Khanchi, M. Faraji and A. Saleh, J. Chromatogr. A, 1217, 2358 (2010).

27. S.Z. Mohammadi, D. Afzali, M.A. Taher and Y.M. Baghelani, Microchim. Acta, 168, 123 (2010).

28. P. Liang and L. Peng, Microchim. Acta, 168, 45 (2010).

29. J. Ma, J. Zhang, X. Du, X. Lei and J. Li, Microchim. Acta, 168, 153 (2010).

30. M. Soylak and E. Yilmaz, Desalination, 275, 297 (2011).

TABLE-3

COMPARISON OF THE PROPOSED METHOD WITH OTHER REPORTED METHODS FOR PRECONCENTRATION OF SILVER

\begin{tabular}{|c|c|c|c|c|c|c|c|c|}
\hline System & $\begin{array}{c}\text { Analysis } \\
\text { method }\end{array}$ & $\begin{array}{c}\text { Sample } \\
\text { volume }(\mathrm{mL})\end{array}$ & $\begin{array}{l}\text { Extraction } \\
\text { time (min) }\end{array}$ & $\begin{array}{c}\text { Enrichment } \\
\text { factor }\end{array}$ & $\begin{array}{c}\text { RSD } \\
(\%)\end{array}$ & $\begin{array}{c}\text { Linear range } \\
\left(\mu \mathrm{gL}^{-1}\right)\end{array}$ & $\begin{array}{c}\text { LOD } \\
\left(\mu \mathrm{g} \mathrm{L}^{-1}\right)\end{array}$ & Ref. \\
\hline $\mathrm{CPE}$ & FAAS & 10 & 25 & 43 & 2.14 & $3.0-200.0$ & 0.56 & 50 \\
\hline $\mathrm{CPE}$ & FAAS & 15 & 66 & 42 & 2.1 & - & 1.40 & 51 \\
\hline Coprecipitation-FI & FAAS & - & 5 & 26 & 2 & - & 0.60 & 52 \\
\hline LLE & FAAS & - & 12 & 30 & - & - & 13.0 & 53 \\
\hline LLE & FAAS & 9 & 6 & 20 & 4.7 & $30.0-160.0$ & 5.00 & 54 \\
\hline Ligandless DLLME & FAAS & 8 & 7 & 16 & 1.5 & $5.0-2000.0$ & 1.20 & 5 \\
\hline
\end{tabular}


31. J.L. Anderson, D.W. Armstrong and G.T. Wei, Anal. Chem., 78, 2892 (2006).

32. K.N. Marsh, J.A. Boxall and R. Lichtenthaler, Fluid Phase Equilib., 219, 93 (2004)

33. S. Pandey, Anal. Chim. Acta, 556, 38 (2006).

34. A. Berthod, M.J. Ruiz-Ángel and S. Carda-Broch, J. Chromatogr. A, 1184, 6 (2008)

35. R. Liu, J.-F. Liu, Y.-G. Yin, X.-L. Hu and G.-B. Jiang, Anal. Bioanal. Chem., 393, 871 (2009).

36. H. Abdolmohammad-Zadeh and E. Ebrahimzadeh, Cent. Eur. J. Chem., 8, 617 (2009).

37. H. Zhao, S.Q. Xia and P.S. Ma, J. Chem. Technol. Biotechnol., 80, 1089 (2005)

38. J.H.Wang, D.H. Cheng, X.W. Chen, Z. Du and Z.L. Fang, Anal. Chem., 79, 620 (2007).

39. X.Q. Sun, A.M. Xu, J. Chen and D.Q. Li, Chin. J. Anal. Chem., 35, 597 (2007).

40. Z.J. Li, J. Chang, H.X. Shan and J.M. Pan, Rev. Anal. Chem., 26, 109 (2007).

41. C.L. Ye, Q.X. Zhou and X.M. Wang, Anal. Chim. Acta, 572, 165 (2006).

42. H.E. Aguilera, R. Lucena, S. Cárdenas and M. Valcárcel, J. Chromatogr. A, 1201, 106 (2008).
43. L.B. Xia, X. Li, Y.L. Wu, B. Hu and R. Chen, Spectrochim. Acta B, 63, 1290 (2008).

44. F.Q. Zhao, S. Lu, W. Du and B.Z. Zeng, Microchim. Acta, 165, 29 (2008).

45. M. Baghdadi and F. Shemirani, Anal. Chim. Acta, 613, 56 (2008).

46. Q.X. Zhou, H.H. Bai, G.H. Xie and J.P. Xiao, J. Chromatogr. A, 1177, 43 (2008)

47. Q.X. Zhou, H.H. Bai, G.H. Xie and J.P. Xiao, J. Chromatogr. A, 1188, 148 (2008)

48. Sh. Li , Sh. Cai, W. Hu, H. Chen and H. Liu, Spectrochim. Acta B, 64, 666 (2009).

49. J.L. Anderson, D.W. Armstrong and G.-T. Wei, Anal. Chem., 78, 2892 (2006).

50. J.L. Manzoori and G. Karim-Nezhad, Anal. Chim. Acta, 484, 155 (2003).

51. M. Ghaedi, A. Shokrollahi, Kh. Niknam, E. Niknam, A. Najibi and M. Soylak, J. Hazard. Mater., 168, 1022 (2009).

52. X.Q. Mao, H.W. Chen and J.S. Liu, Microchim. J., 59, 383 (1998)

53. C.T. Camagong and T. Honjo, Anal. Bional. Chem., 373, 856 (2002).

54. O.D. Sant'Ana, A.L.R. Wagener, R.E. Santelli, R.J. Cassella, M. Gallego and M. Valcarcel, Talanta, 56, 673 (2002). 